Litherland, M.M., and Klemperer, S.L., 2017, Crustal structure of the Ruby Mountains metamorphic core complex, Nevada, from passive seismic imaging: Geosphere, v. 13, no. 4, p. 1-18

\title{
Supplemental Figures to Crustal Structure of the Ruby Mountains Metamorphic Core Complex, Nevada, from Passive Seismic Imaging
}

\author{
Mairi M. Litherland ${ }^{1}$ and Simon L. Klemperer ${ }^{1}$

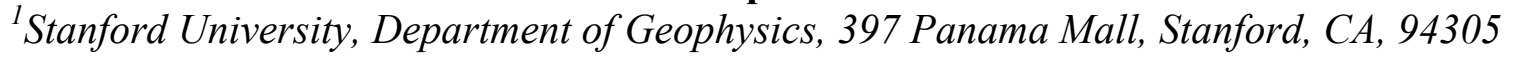

Figure S1. Test of different velocity models for common-conversion point stacking. (A) Vp/Vs ratio of 1.76 reproduced from Figure 7 with velocity model of Figure 9A; (B) same as (A) but with low wave-speed basin added at surface, i.e. velocity model of Figure 9C; (C) same as (A) but with $\mathrm{Vp} / \mathrm{Vs}$ ratio of 1.86. All annotations as in Figure 7 for comparison. (B) shows no observable change in Moho depth and (C) shows a Moho depth decrease of $\sim 3 \mathrm{~km}$; this is not enough to account for the Moho depth variations we observe, e.g. at the crustal welt. For TA stations, we calculated our own RFs for CCP imaging.

Figure S2. Results of H-k analysis superimposed on common conversion point (CCP) images from Figure 6; depth is shown by depth of circle and $\mathrm{Vp} / \mathrm{Vs}$ ratio is shown by color of circle. Circles with white outline are automated H-k estimates at the TA stations using data from the IRIS EARS project (http://ears.iris.washington.edu/) and show the problems of choosing the largest amplitude in the grid search without considering other factors: the estimate at $\mathrm{O} 11$ is consistent with our CCP image whereas estimates at O12, N11, and N12 are not (the depth separation between IRIS EARS estimates and our CCP image of the Moho far exceeds the published uncertainty in EARS H-k results). Our H-k depths mostly match observed Moho from $\mathrm{CCP}$ images. $\mathrm{Vp} / \mathrm{Vs}$ ratios are mostly near 1.76 with some outliers; however the variation is not systematic. Large changes over short distances (e.g. from 1.6 at B03 to 1.8 at B04, just 5km apart, and from 1.9 at $\mathrm{C} 03$ to 1.6 at $\mathrm{C} 04$, also $\sim 5 \mathrm{~km}$ apart) most likely result from the nonuniqueness of $\mathrm{H}-\mathrm{k}$ solutions rather than true geological variation.

Figure S3. Example of a single good-quality SKS event from station A03. (A) Filtered waveform rotated to event backazimuth. Dashed blue line is radial component, solid red line is transverse. (B) Results from the rotation correlation method, showing: 1) motion along fast (red) and slow (blue) axes, corrected for time delay (for a good-quality result, the two curves match); 2) transverse component before (blue) and after (red) time correction (for good-quality results, red curve has near-zero amplitude); 3) particle motion before (blue) and after (red) correction (for good-quality results, red path is a straight line); 4) map showing solution on coordinates of fast axis direction vs. time delay. (C) Same as (B), but for the minimum energy method.

Figure S4. (A) CCP image of TA station N11, with H-k results superimposed on it. Circle with white border is the automated IRIS EARS H-k estimate (from http://ears.iris.washington.edu/), circles with black borders are three possible results from our analysis. (B) H-k stacking result for N11 with white dots showing three local maxima. Multiple local maxima make it difficult to automatically ascertain true $\mathrm{H}-\mathrm{k}$ values, but our single-station image clearly shows separate converters $\mathrm{m} 2 \mathrm{a}$ and $\mathrm{m} 2 \mathrm{~b}$ that seem further validated by $\mathrm{H}-\mathrm{k}$ maxima with appropriate $\mathrm{Vp} / \mathrm{Vs}$ ratios of $1.8-1.9$. 


\section{Figure S1}

Same as Fig. 7

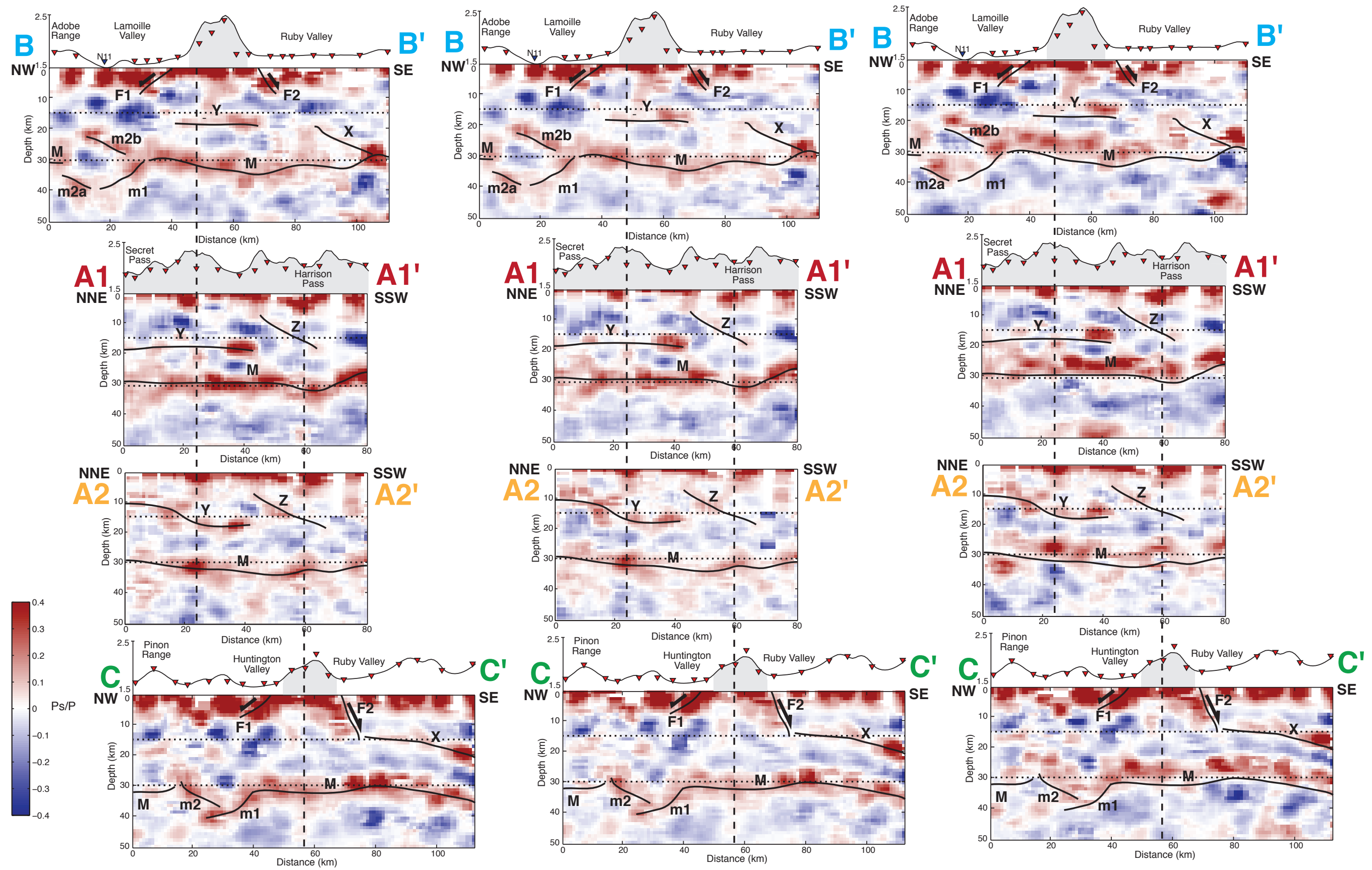



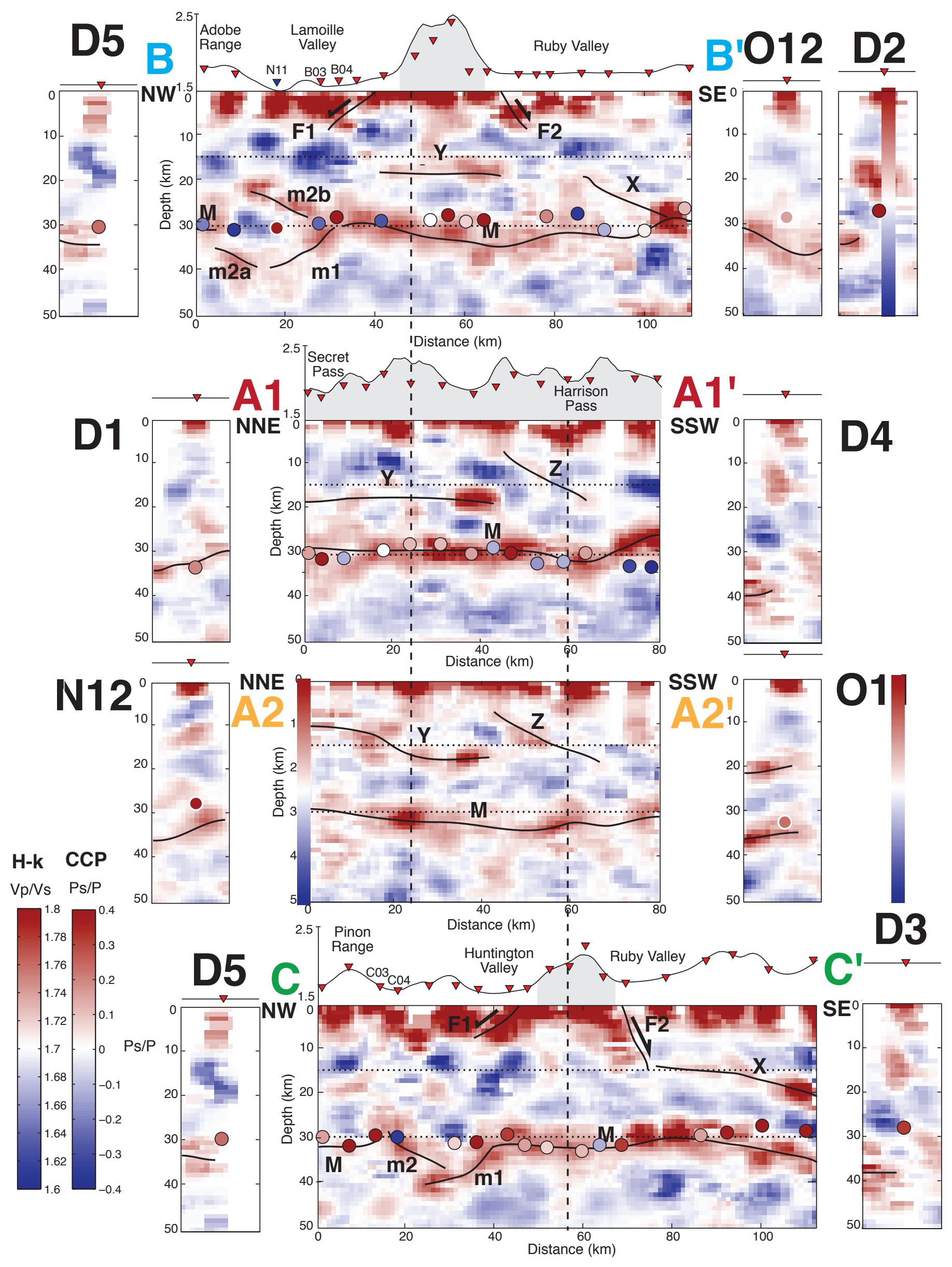


\section{Figure S3}

A

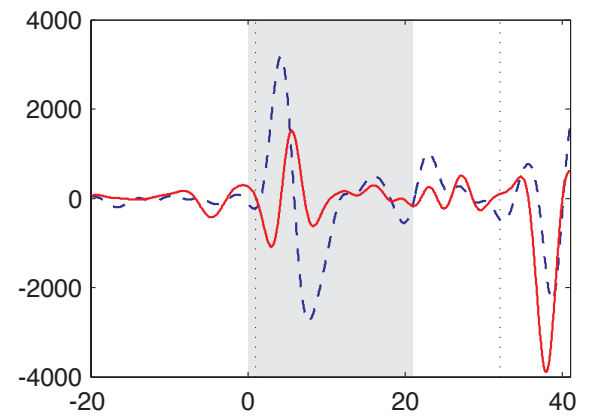

\section{RMSE A03}

Example of 'good' SKS result

B
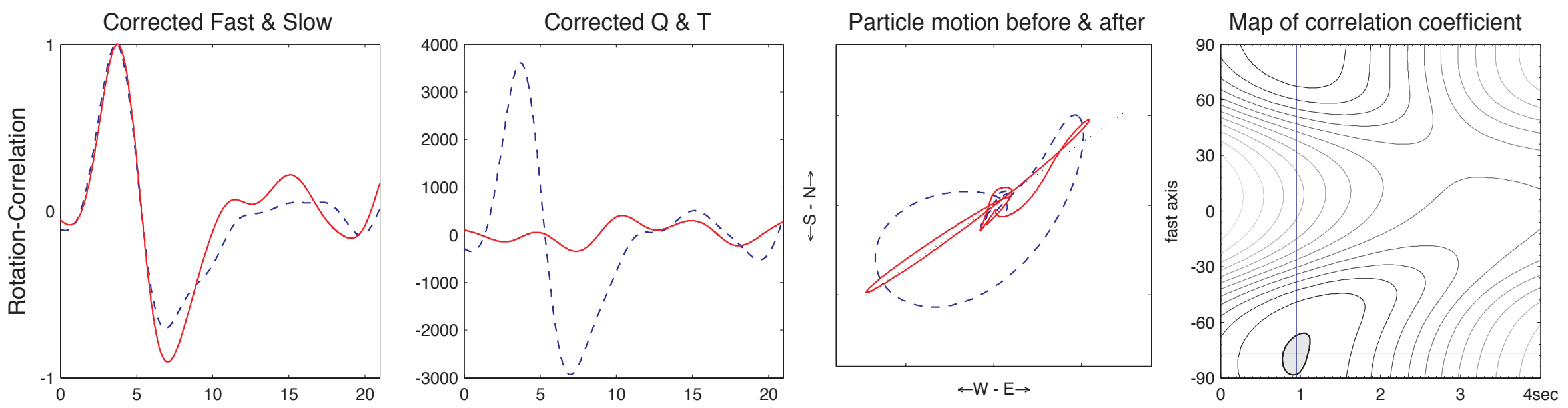

C
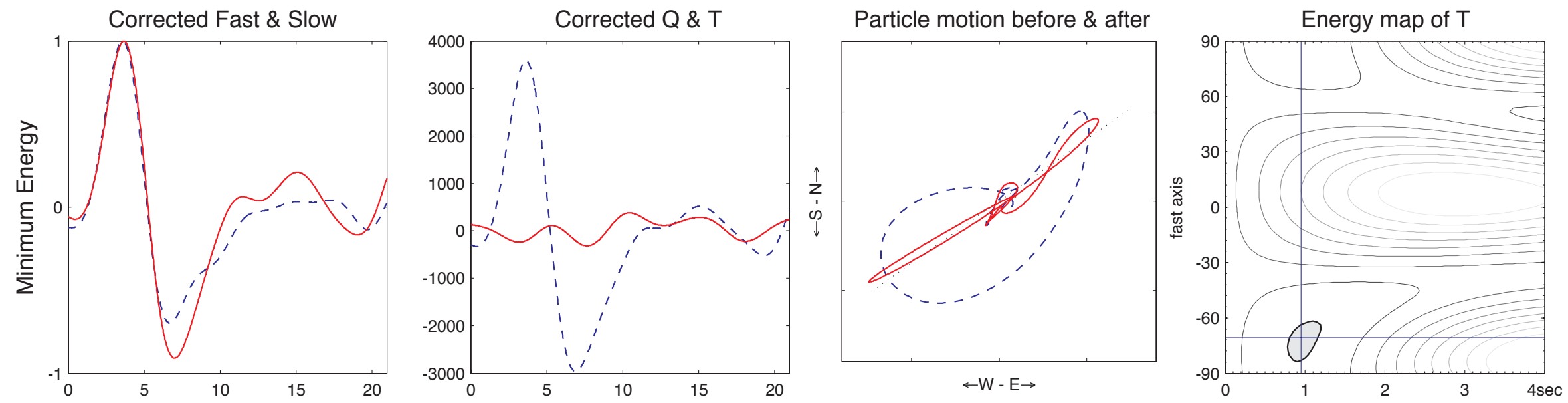
Figure S4

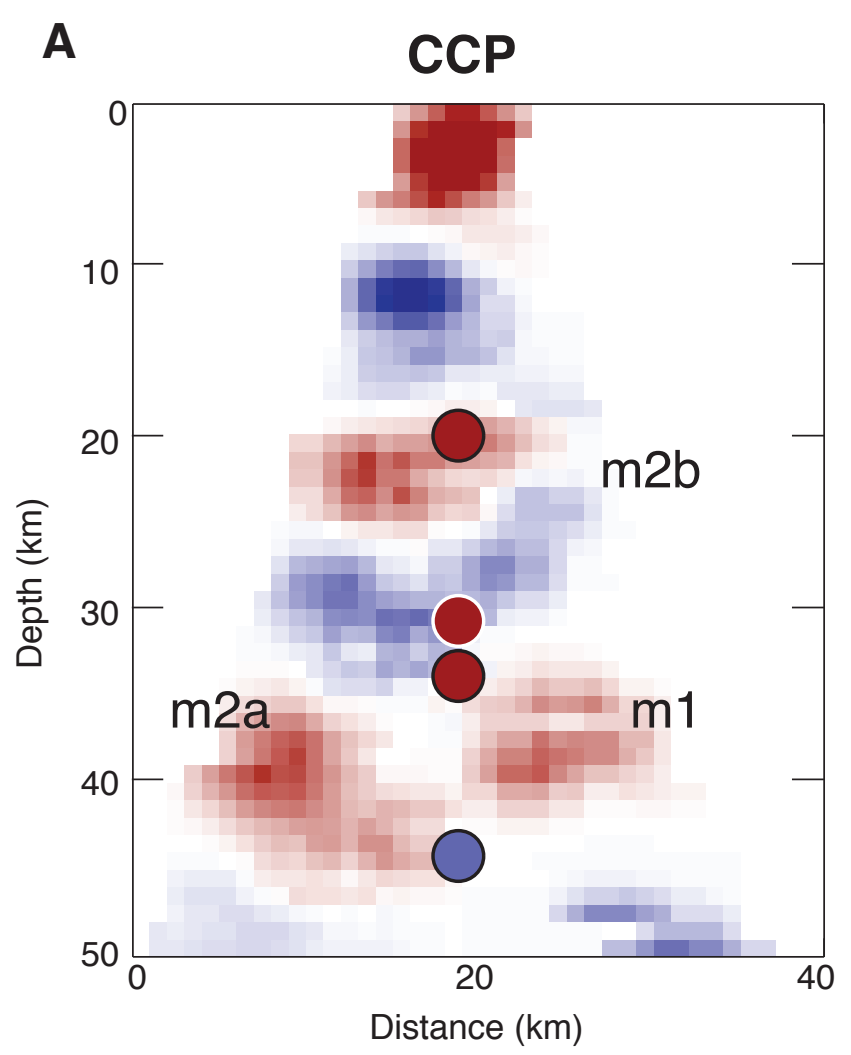

B

N11

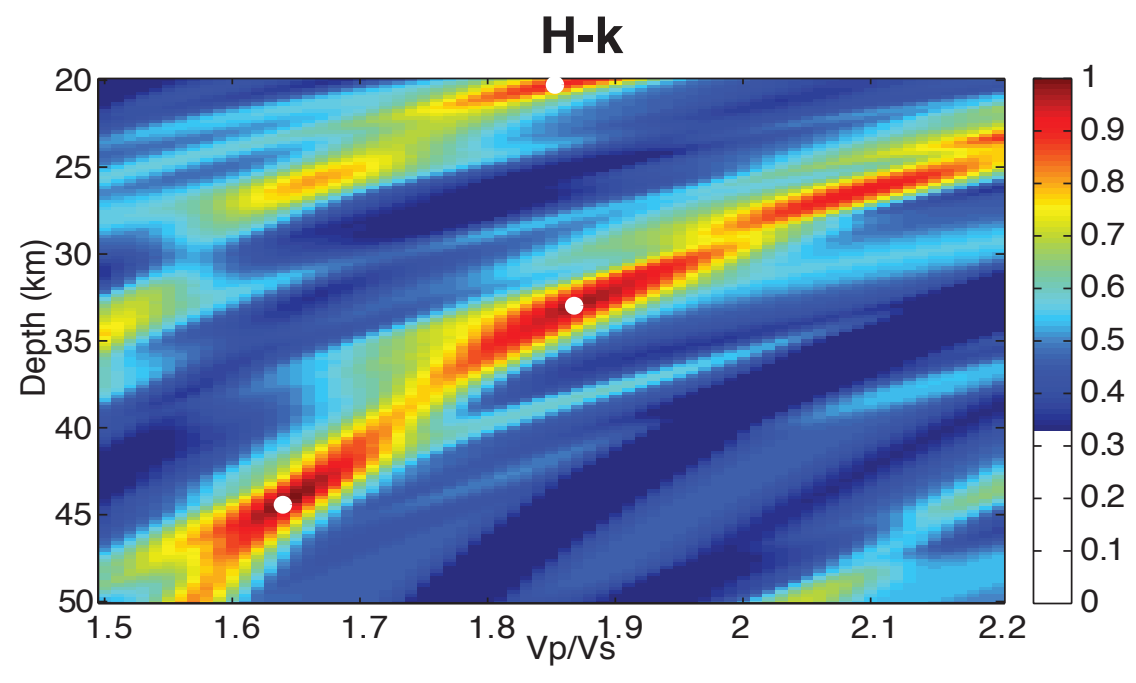

